\title{
'Race' or place? Explaining ethnic variations in childhood pedestrian injury rates in London
}

\author{
Rebecca Steinbach ${ }^{\mathrm{a}}$, Judith Green ${ }^{\mathrm{a}, *}$, Phil Edwards ${ }^{\mathrm{b}}$, Chris Grundy ${ }^{\mathrm{a}}$ \\ a Department of Public Health \& Policy, London School of Hygiene E Tropical Medicine, Keppel Street, London WC1E 7HT, United Kingdom \\ ${ }^{\mathrm{b}}$ Department of Epidemiology E Population Health, London School of Hygiene E' Tropical Medicine, Keppel Street, London WC1E 7HT, United Kingdom
}

\section{A R T I C L E I N F O}

\section{Article history:}

Received 26 March 2009

Received in revised form

30 July 2009

Accepted 15 August 2009

\section{Keywords:}

Ethnicity

Pedestrians

Children

Area deprivation

Road environment

Wounds and Injuries

\begin{abstract}
A B S T R A C T
There is a substantial literature on socio-economic inequalities in injury rates, but less on ethnic differences. Using police records of road injuries to examine the relationships between pedestrian injury, area deprivation and ethnicity we found that, in London, children categorised as 'Black' had higher injury rates than those categorised as 'White' or 'Asian', and that living in less deprived areas did not protect 'Black' children from higher risk. Ethnic differences in injury rates cannot be explained by minority ethnic status or area deprivation, but are likely to result from the complex ways in which ethnicity shapes local experiences of exposure to injury risk.
\end{abstract}

(c) 2009 Elsevier Ltd. All rights reserved.

\section{Introduction}

Despite declines in rates of injury over the last twenty years, road traffic injuries remain a major contributor to childhood mortality and morbidity in high income countries (WHO, 2004). This burden is not distributed equally, with studies in a number of countries documenting persisting inequalities in the risk of injury and death (Laflamme and Diderichsen, 2000; Reimers and Laflamme, 2005; Rivera and Barber, 1985; Edwards et al., 2008). In the United Kingdom (UK), local and national studies have identified higher pedestrian injury rates in areas characterised by high levels of deprivation (Grayling et al., 2002; Lyons et al., 2003; Edwards et al., 2008). Analysis of injury mortality data (Edwards et al., 2006) suggests that there are particularly steep socioeconomic gradients for child pedestrians.

To date, there has been far less epidemiological research on ethnicity and road injury risk, and the findings are less clear cut than those on deprivation. Although many international studies suggest that minority ethnic groups are at higher risk than the majority population (Schiff and Becker, 1996; Campos-Outcalt et al., 2002; Stevens and Dellinger, 2002; Cercarelli and Knuiman., 2002; Braver, 2003; Stirbu et al., 2006; Savitsky et al., 2007), others have identified some minority groups at lower risk

\footnotetext{
* Corresponding author. Tel.: +440207927 2024; fax: +4402074365389.

E-mail address: Judith.Green@LSHTM.ac.uk (J. Green).
}

(Campos-Outcalt et al., 2003). Within the UK, one case-control study found 'non-White' children at higher risk (Christie, 1995), and one local study found 'Asian', but not other ethnic minority, children at higher risk of road traffic injury (Lawson and Edwards, 1991). There are a number of national and regional policy incentives for examining whether there is evidence for ethnic inequalities in injury in the UK, with statutory agencies charged with reducing inequality in health outcomes by targeting those at highest risk and working with communities to develop appropriate services (Department of Health, 2003; Mayor of London, 2008). Nearly half of all non-White ethnic minorities in the UK live in London, and more than one in three London residents belong to a minority ethnic group (Bains and Klodawski, 2007). Transport for London, the body responsible for delivering the Mayor of London's transport strategy (Mayor of London, 2001), commissioned this study in response to concerns about whether road safety gains were being shared equally across London's diverse population.

Research on the relationships between ethnicity and health outcomes presents conceptual, methodological and practical challenges. There is now a growing body of evidence documenting ethnic differences in health outcomes in the UK (Marmot et al., 1984; Davey Smith et al., 2000; Nazroo, 2001; Erens and Primatesta, 2001) but, as Bhopal (1997) has cautioned, there is a real risk of 'black box epidemiology' if we merely document 'differences' between poorly defined and conceptualised groupings. To be useful for policy and practice in addressing inequalities 
in health, research needs to be directed at not only documenting inequalities, but unpacking the mechanisms which potentially link components of ethnicity with particular health outcomes. This is a challenge on a number of levels. First, a priori assumptions of ethnic differences may bias research efforts towards looking at how minority ethnic groups compare (poorly) to majority populations and, as Bradby (2003) notes, acknowledging discrimination whilst not perpetuating it is difficult. Second, as an epidemiological variable, ethnicity is inherently problematic. Ethnicity, referring to 'the identification with a social group ... on the basis of shared values, beliefs, customs, language and lifestyle' (Nazroo, 2004, p. 13), includes components related to nationality, skin colour, country of origin of self and ancestors, and religion. As a multidimensional and fluid concept, with meanings influenced by both historical value systems and the current social and political context (Bradby, 2003), ethnic identities are of course time and place specific. The ways in which ethnicity potentially influences health outcomes theoretically relate to these aspects of identity, but also (more plausibly, for many health outcomes) to ethnicity as 'structure' (Karlsen and Nazroo, 2002), including components such as associations with socio-economic factors and experiences of racism.

\subsection{A model of potential links between ethnicity and child pedestrian injury risk}

In terms of conceptualising how ethnicity might relate to pedestrian injury as an outcome, there are a number of potential causal pathways relating to ethnicity as both 'structure' and 'identity'. The determinants of the relative risk of being injured as a pedestrian include three factors: the road environment (how many roads and junctions, the volume and speed of traffic); an individual's exposure to that environment (how often they are on or near the road as a pedestrian); and their behaviour on or near roads. These three factors are inter-related, in that behaviour and levels of exposure are to some extent determined by the perceived dangerousness of the road environment. Fig. 1 summarises some of pathways by which ethnicity might influence these variables.

First, ethnicity is often associated with deprivation, both at area level and individually, at household level. A long standing debate in research on ethnicity and health has been the extent to which observed differences reflect socio-economic inequalities (Nazroo, 1998, 2001; Davey Smith, 2000; Ahmad and Bradby, 2007). At an area level, given the known associations between injury and area deprivation (Edwards et al., 2008), and the fact that ethnic minorities tend to live in more deprived areas in the UK (Prime Ministers Strategy Unit, 2005), with particularly steep gradients in London (Table 1), any differences found in pedestrian injury by ethnicity might simply be a reflection of area effects relating to local road environments. Evidence suggests that a higher density of major roads, high vehicle speeds, high junction density, the presence of parked cars, the presence of bus stops, low minor road density, high employment density, and low residential population density are associated with increased pedestrian injury risk (Noland and Quddus, 2005; Grayling et al., 2002; Agran et al., 1996; Roberts et al., 1995). Thus ethnicity may be merely a proxy for the area effects of 'place', if minority ethnic communities live in areas more likely to have these road environments.

However, it is also known that injury risk is associated independently with individual, or household, socio-economic deprivation as well as area effects (Reading et al., 1999; Haynes et al., 2003). At the household level, associations with injury risk have been found for both number of parents in the household (Haynes et al., 2003) and employment status (Edwards et al., 2006). These variables are also likely to vary across ethnic groups. Pedestrian exposure is likely to be an important mediator of relationships between deprivation and risk, with Sonkin et al. (2006) finding, for instance, higher levels of walking in households with unemployed adults, in rented rather than owneroccupied accommodation and in households with no access to a car. Within the UK, there are large ethnic differences in household car availability, with the National Travel Survey (Department for

Table 1

Average percentages of Lower Super Output Area populations that are 'Black' and 'Asian' by deciles of deprivation (Edwards et al., 2007).

\begin{tabular}{lcc}
\hline Deprivation deciles & Percentage 'Black'(SD) & Percentage ‘Asian' (SD) \\
\hline 1 & $1.5(1)$ & $6.6(7)$ \\
2 & $2.7(2)$ & $7.8(9)$ \\
3 & $4.8(5)$ & $11.7(13)$ \\
4 & $6.8(6)$ & $12.8(13)$ \\
5 & $9.2(7)$ & $14.5(15)$ \\
6 & $11.1(7)$ & $12.5(15)$ \\
7 & $13.2(8)$ & $12.7(14)$ \\
8 & $16.0(10)$ & $13.0(17)$ \\
9 & $20.8(12)$ & $12.2(14)$ \\
10 & $23.2(12)$ & $15.6(17)$ \\
\end{tabular}

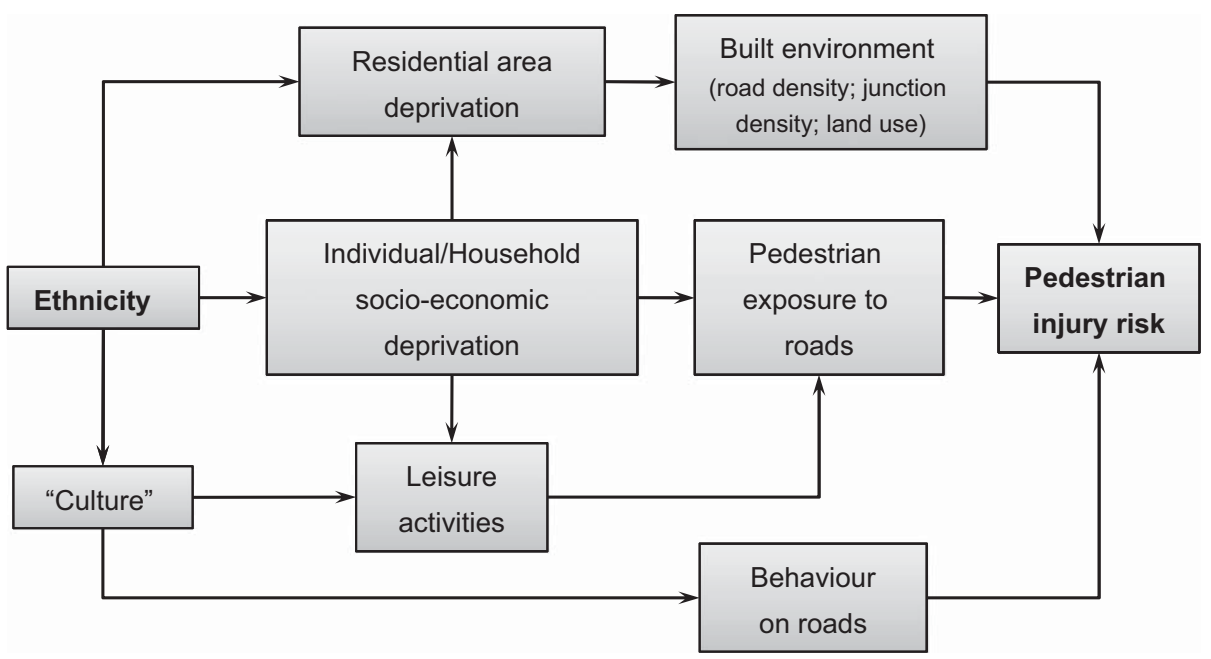

Fig. 1. A model of causal pathways linking ethnicity to pedestrian injury risk 
Transport, 2006) identifying highest rates of car ownership in those of Indian and White British background (86 and 82\%, respectively) and lowest in those of African or Caribbean background (54 and $62 \%$, respectively).

Other candidate explanations relate to causal pathways that link cultural components of ethnicity to risk. 'Culture' is a rather inadequate catch-all term for those aspects of lifestyle that might be shared within ethnic groups, but it could be hypothesised that for instance, different ethnic identities may be associated with factors that directly influence injury risk, such as different attitudes to risk taking (which might influence road crossing behaviour) (see for example, Factor et al., 2008), or different preferences for leisure activities (such as those centred on outdoor, public space exposed to traffic risk). These 'cultural' factors may of course be mediators of deprivation effects, in that differential access to indoor space or private gardens may shape preferences for outdoor activity, and structural factors may make risk taking behaviour more prevalent. From a policy perspective, candidate explanations which relate to behaviour or cultural preferences are perhaps less interesting, for two reasons. First, they often relate to factors that are less amenable to social intervention, given the limited evidence for the effectiveness of educational interventions directed at changing behaviour compared with interventions addressing the road environment (Duperrex et al., 2002; Bunn et al., 2003). Second, even if interventions were effective in changing behaviour, it might well be inappropriate to do so. A higher propensity to enjoy outdoor activity, for instance, is likely to bring health benefits as well as health risks. The challenge is to provide an environment in which such activities can be done without incurring additional risk, rather than to reduce children's use of outdoor space.

The aims of this study were driven to a large extent by policy needs. There was a desire to identify whether there were ethnic inequalities in outcomes, and the first aim was therefore to identify whether it was possible, using available datasets, to identify credible evidence of differences in pedestrian injury rates by ethnicity. Second, given that there is a considerable amount of evidence that interventions addressing the road environment are the most effective for reducing injuries (Bunn et al., 2003; Morrison et al., 2003) we aimed to identify how far any differences by ethnicity could be explained by area deprivation. If area deprivation accounted for any differences found across ethnic groups, inequalities could potentially be ameliorated through policies to prioritise deprived neighbourhoods for traffic interventions.

\subsection{Measures of ethnicity}

A major challenge to such a study is that the problems of inadequate conceptualisation of ethnicity lead directly to difficulties in operationalisation for empirical research. Population denominator data come from self-identified fixed response categories used in the decennial census, which reflect the multiple ways in which British minority ethnic groups are differentiated (by skin colour, ethnic identity, religion and nationality, for instance). This strategy is subject to limitations given that fixed response census categories can neither reflect the contextual nature of claims to particular ethnic identities, nor adequately capture mixed ethnic identities. A more significant practical challenge is that few routine datasets in the UK utilise the same categories. The most comprehensive data source for health care use, Hospital Episode Statistics (HES), which records admissions to National Health Service hospitals, only utilised comparable codes to those of the Census from 2001, and there are wide variations in terms of completeness of coding and historically a high proportion of missing ethnic codes (around 36\%) for under 15 year olds (HES Online, 2004).

An alternative for examining road traffic injuries is STATS19 data, from police records of road collisions. STATS19 is the official dataset of personal injury road collisions and resulting casualties that occur on the public highway in the UK. Although data on the ethnicity of persons involved in road traffic collisions is not available for most of the UK, London Metropolitan police officers have recorded the ethnicity of casualties since 1995. Initially, these data appear of limited value. The measure of ethnicity used is the six-category Police National Computer 'Identity Code', which is designed for description for crime detection and prevention, rather than monitoring, purposes (ACPO, 2001). The categories (Table 2) rely on observer identification of physical attributes, rather than on self-identification, as in the census. It is unknown how, in practice, London's police officers do distinguish people as, for instance, 'Dark-skinned European' or 'Arab'. These categories certainly do not reflect how most people would define their own ethnicity, and there are no population level data that use them. Despite these weaknesses, STATS19 data do have a number of advantages compared with HES data. They have a reasonable coverage of ethnicity, and may be less subject to the selection bias inherent in HES from differences in help-seeking behaviour, which are associated with distance to hospital, deprivation and ethnicity. Given the availability and coverage of STATS19, we were interested to see whether these data could be used to examine the relationships between ethnicity, area deprivation and road environments.

\section{Methods}

We obtained an extract of STATS19 data from the London Road Safety Unit that included all reported casualties and collisions occurring in London during 1996-2006. Where possible, we removed non-London residents (e.g. visitors) using their postcode of residence. Casualties were included in the analysis if aged 0-15 years and injured as pedestrians. Each casualty was assigned to a lower super output area (LSOA) based on the Ordnance Survey grid reference of the location where the collision occurred. LSOAs are geographic areas containing an average of 1500 people, defined by the Office of National Statistics using measures of population size, mutual proximity and homogeneity. There are 4765 LSOAs in London, within 33 boroughs. Collision location was used in the analysis due to the low levels of completeness of recording home postcodes in some boroughs, and because children are known to be injured as pedestrians close to home (Edwards et al., 2007). LSOAs in the City of London were excluded from the analysis as this borough tends to have a large day-time population and a small resident population. The level of deprivation of each LSOA was scored using the Index of Multiple Deprivation 2004 (IMD) (Noble et al., 2004). LSOAs were ranked according to IMD score and divided into deciles ( 1 least deprived to 10 most deprived).

\subsection{Population estimates and rates}

To derive population rates, we first mapped the majority of the STATS19 categories pragmatically to aggregated groupings used by the Greater London Authority, which are drawn from the 2001 Census categories that are most common in London (Table 2) (Bains and Klodawski, 2007). We then derived three broad categories of ethnicity, which we have called 'White', 'Black, and 'Asian', based on these mappings of STATS19 codes to aggregated census categories. We also conducted a sensitivity analysis to compare the results from alternative mappings of STATS19 codes 
Table 2

Derivations of ethnic groups from mapping of STATS19 ethnicity categories to Greater London Authority (GLA) aggregations of census ethnic group codes.

\begin{tabular}{|c|c|c|c|}
\hline This study & STATS19 & GLA (Aggregated Ethnic Group) & Census 2001 \\
\hline White & $\begin{array}{l}\text { White-skinned European } \\
\text { Dark-skinned European }\end{array}$ & White & $\begin{array}{l}\text { British } \\
\text { Irish } \\
\text { Other White }\end{array}$ \\
\hline Black & Afro-Caribbean & $\begin{array}{l}\text { Black Caribbean } \\
\text { Black African } \\
\text { Other Black }\end{array}$ & $\begin{array}{l}\text { Caribbean } \\
\text { African } \\
\text { Other Black } \\
\text { Mixed-White \& Black Caribbean } \\
\text { Mixed-White \& Black African }\end{array}$ \\
\hline Asian & Asian & $\begin{array}{l}\text { Indian } \\
\text { Pakistani } \\
\text { Bangladeshi } \\
\text { Other Asian }\end{array}$ & $\begin{array}{l}\text { Indian } \\
\text { Pakistani } \\
\text { Bangladeshi } \\
\text { Other Asian } \\
\text { Mixed-White \& Asian }\end{array}$ \\
\hline (Excluded from main analysis) & $\begin{array}{l}\text { Oriental } \\
\text { Arab }\end{array}$ & $\begin{array}{l}\text { Chinese } \\
\text { Other } \\
\text { Other Mixed }\end{array}$ & $\begin{array}{l}\text { Chinese } \\
\text { Other } \\
\text { Mixed-Other }\end{array}$ \\
\hline
\end{tabular}

to census categories. Age specific population data are not available at LSOA level by ethnic group, so the population of 'White', 'Black', and 'Asian' children in each LSOA was estimated by multiplying the numbers of children resident in each LSOA by the percentages of residents of all ages that are 'White', 'Black', or 'Asian' (both from the 2001 Census). The estimates of LSOA-level ethnic group child populations were then scaled to sum to the available borough level totals, to allow for ethnic differences in family size.

\subsection{Road environment and area characteristic variables}

Based on evidence from the literature, we selected available road environment and area characteristic variables with known associations with injury risk. These included: density of road junctions, A roads and minor roads in the LSOA, the proportion of postcodes in an LSOA characterised as business, and the area (in square metres) of an LSOA. Information on vehicle speeds and traffic flows is only available at borough level and is unlikely to reflect accurately the road environment in each individual LSOA. These borough level variables were not therefore included in the main model, but were included in a sensitivity analysis. To create variables describing the road environment in an LSOA, and in adjacent LSOAs, current road network information from the Integrated Transport Network (ITN) supplied by Ordnance Survey was overlaid with LSOA boundaries provided by the census in ArcView GIS. Borough level estimates of traffic flow and traffic speeds were provided by Road Network Monitoring, Transport for London.

\subsection{Statistical analysis}

Negative binomial multivariable regression was used to estimate models of the number of children of each ethnic group injured as pedestrians in each LSOA. We estimated injury rate ratios, with $95 \%$ confidence intervals, comparing rates in each decile of LSOAs with the rate in the least deprived decile, adjusting for road environment and area characteristic variables (see statistical appendix for details of model specification). Robust standard errors were used to allow for within-borough correlations in LSOA injury rates. Finally, a likelihood ratio test of two Poisson regression models of pedestrian injury risk, one including a term for interaction between deprivation and ethnicity, and the other excluding the interaction term, was used to assess whether the relationship between deprivation and injury was similar across ethnic groups. Approval for the study was obtained from the London School of Hygiene \& Tropical Medicine Research Ethics Committee.

\section{Results}

Between 1996 and 2006 there were 22,121 pedestrian causalities aged $0-15$ years recorded in London (excluding City of London), with 11,206 identified as 'White', 5400 as 'Black', 2511 as 'Asian' and 477 as either 'Arab' or 'Oriental'. A total of 2527 (11\%) casualties had missing ethnicity codes. Based on our initial pragmatic mapping, average annual pedestrian injury rates were higher in 'Black' children (176 per 100,000 children; 95\% confidence interval 172-181), than in either 'White' children (118 per 100,000 children; 95\% CI 116-121) or in 'Asian' children (91 per 100,000 children; $95 \%$ CI 88-95).

The size of these ethnic differences was changed using alternative groupings of STATS19 codes and census derived categories. For example: when the STATS19 category 'Darkskinned European' was excluded from the 'White' group, the rate decreased to 109 (95\% CI 107-111) per 100,000 children; when 'Arab' and 'Oriental' were included in the 'Asian' group, the rate increased to 109 (95\% CI 105-113) per 100,000; when 'Darkskinned European' was included in the 'Asian' group, the rate increased to 124 (95\% CI $120-128$ ) per 100,000 . However, rates in the 'Black' group remained higher than all other ethnic groupings in all except one mapping. When records with missing ethnicity codes were included in the 'Asian' group, the rates in the 'Asian' group, 184 (95\% CI 179-189) per 100,000, became equivalent to that in the 'Black' group, 176 (95\% CI 172-181) per 100,000.

\subsection{The relationship between injury risk and deprivation for each ethnic grouping}

Based on our pragmatic grouping of ethnicity categories, Fig. 2 shows pedestrian injury rates by deprivation decile separately for each ethnic group, unadjusted for road environment variables. In least deprived deciles, 'Black' child pedestrian injury rates were highest, and in the two most deprived deciles 'Black' and 'White' child pedestrian injury rates were similar. The pedestrian injury rates in 'Asian' children were lower than in either 'Black' or 'White' children across all deprivation deciles.

After adjusting for road environment and area characteristic variables, we looked separately at the relative risks for pedestrian 
injury across deprivation deciles for each ethnic grouping (Fig. 3). For 'White' pedestrians, there was a linear relationship between deprivation and injury rates, with the rate in the most deprived decile 2.90 (95\% CI 2.53-3.32) times higher than that in the least deprived decile. For 'Asian' child pedestrians, there was a similar relationship between deprivation and injury risk, with the rate in the most deprived decile 2.34 (95\% CI 1.70-3.21) times that in the least deprived decile. However, for 'Black' children, no relationship was observed between deprivation and injury rates, with no evidence for a difference in rates between the most deprived and least deprived deciles (rate ratio 1.01 ; 95\% CI 0.75-1.37).

The relationship between child pedestrian injury and deprivation in the 'White' and 'Asian' groups was not substantially changed when using alternative mappings of the STATS19 ethnic codes. There was good evidence, from the test for interaction, that the relationship between level of area deprivation and injury rates differs by ethnic group $(p<0.001)$. There was a reasonably good fit of our model to the data for 'White' child pedestrian injury (Pearson chi-squared $=4921$, residual degrees of freedom $=4745$ ). The fit for 'Black' child pedestrian injury and 'Asian' pedestrians was less good (Pearson chi-squared $=5720$ and 5740, with 4730 and 4738 residual degrees of freedom, respectively).

\subsection{The effect of road environment and area characteristics}

Table 3 shows the effect of the road environment variables and area characteristics on child pedestrian injury independently of

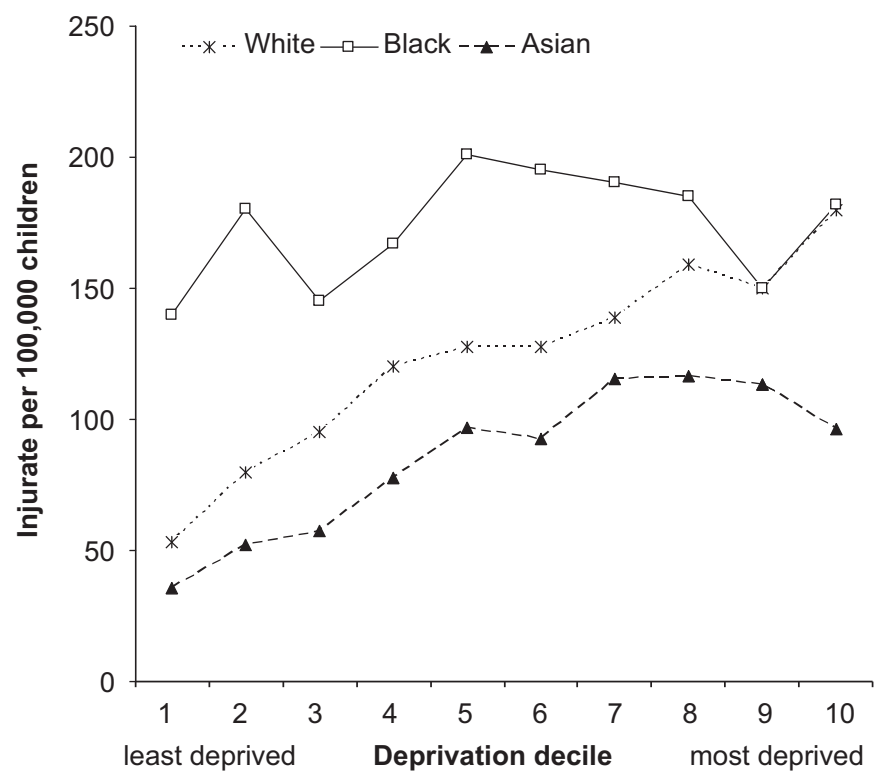

Fig. 2. Pedestrian injury rates per 100,000 children by deprivation decile for each ethnic group (unadjusted for road environment variables) area level deprivation for the three ethnic groupings. The results indicate some evidence that density of A roads in LSOAs (i.e. kilometres of A roads per hectare) was associated with increased injury rates, whereas the density of minor roads was associated with decreased injury risk for all three ethnic groupings. An increase in the proportion of postcodes in an LSOA characterised as 'business' was associated with higher injury rates in children from all three ethnic groups. There was good evidence that higher junction density was associated with higher injury rates in 'White' children. Including borough level data on morning speeds of A roads and traffic flow in the models did not change the model coefficients; that is, relationships between injury and deprivation, road and area variables were unchanged. There was weak evidence that higher speed was associated with increased injury risk in 'White' and 'Asian' children, but decreased injury risk in 'Black' children (results not shown).

\section{Discussion}

We have used STATS19 data first to estimate the rates of pedestrian injury for three broad ethnic groupings of children in London and then to examine the relationship between deprivation and injury risk separately for each ethnic grouping. A common threat to validity in research on ethnicity is numerator-denominator bias, given the reliance in most studies on data from different recording systems for numerators and denominators. Much of the evidence on mortality and ethnicity from the United States, for instance, uses coroner recorded ethnic and race categories (see for instance, Stevens and Dellinger, 2002; Campos-Outcalt et al., 2002, 2003; Braver, 2003), with known problems in reliability when assessed against self-report data for many ethnic groups (Briggs et al., 2005). Even where the same classification systems are used, it is not known how far selfreported ethnicity is reliable over different locations (such as health care facilities and census completion). Given that our denominators were from census population estimates and numerators were derived from police-assigned classifications of what is essentially a measure of observed 'race' rather than ethnicity, and there are no data on how police decisions might relate to self-identified ethnic identity, numerator-denominator bias is a particular threat in this study. We addressed this possible limitation by first deriving a pragmatic mapping of STATS19 ethnic codes to census derived categories, and then testing the robustness of our results by using alternative mappings. These alternatives were more conservative in terms of potentially over-estimating the apparently high rate of 'Black' casualties or under-estimating the lower rates of 'White' and 'Asian' groups. The results suggest that caution is required when comparing the rates of 'White' and 'Asian' child injuries. This is perhaps unsurprising given the difficulty of identifying ethnic identities from observed physical characteristics in ways that are likely to correspond to self-defined ethnicity. However, the alternative
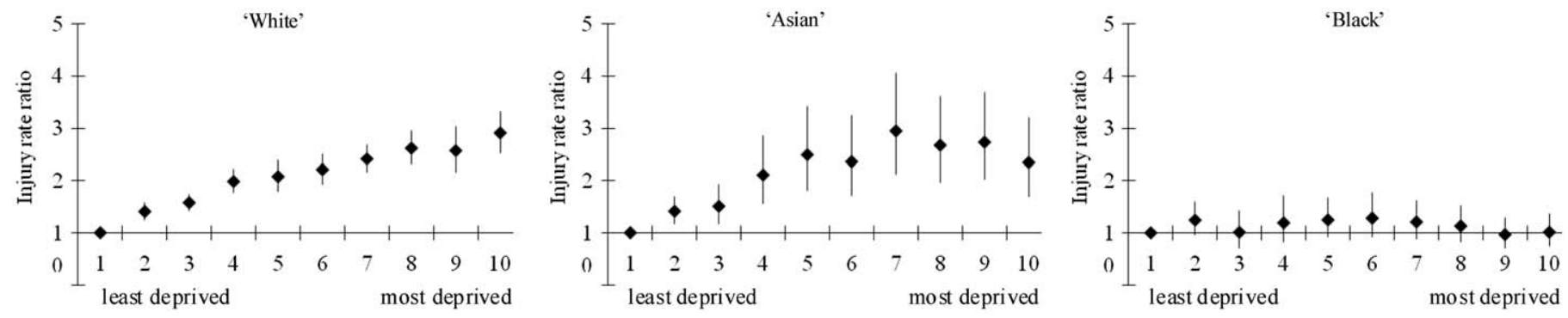

Fig. 3. Injury rate ratios comparing pedestrian injury rates by decile of deprivation with that in the least deprived decile (adjusted for road environment variables). 
Table 3

Rate ratios showing changes in injury rates associated with road environment and area characteristics of LSOAs.

\begin{tabular}{|c|c|c|c|c|c|c|c|c|c|}
\hline \multirow[b]{2}{*}{ Variable } & \multicolumn{3}{|l|}{ White } & \multicolumn{3}{|l|}{ Black } & \multicolumn{3}{|l|}{ Asian } \\
\hline & $\mathrm{RR}$ & $(95 \% \mathrm{CI})$ & $p$-value & $\mathrm{RR}$ & $(95 \% \mathrm{CI})$ & $p$-value & RR & $(95 \% \mathrm{CI})$ & $p$-value \\
\hline Density $^{\mathrm{a}}$ of $\mathrm{A}$ roads & 1.004 & $(1.002-1.006)$ & $<0.001$ & 1.008 & $(1.006-1.010)$ & $<0.001$ & 1.003 & $(1.002-1.005)$ & $<0.001$ \\
\hline Density ${ }^{\mathrm{a}}$ of minor roads & 0.996 & $(0.995-0.998)$ & $<0.001$ & 0.998 & $(0.996-0.999)$ & $<0.001$ & 0.998 & $(0.996-0.999)$ & 0.002 \\
\hline Density $^{\mathrm{b}}$ of road junctions & 1.074 & $(1.014-1.138)$ & 0.015 & 1.046 & $(0.977-1.120)$ & 0.194 & 1.013 & $(0.962-1.067)$ & 0.629 \\
\hline Proportion of postcodes characterised as business & 1.043 & $(1.035-1.051)$ & $<0.001$ & 1.047 & $(1.037-1.056)$ & $<0.001$ & 1.040 & $(1.031-1.049)$ & $<0.001$ \\
\hline Area $\left(\mathrm{m}^{2}\right)$ & 1.000 & $(0.999-1.000)$ & 0.292 & 1.000 & $(0.999-1.000)$ & 0.346 & 0.999 & $(0.998-1.000)$ & 0.258 \\
\hline
\end{tabular}

Rate ratios adjusted for area level deprivation (deciles of IMD) and the other variables shown in the table.

a Density measured as kilometres of road per hectare.

${ }^{\mathrm{b}}$ Density measured as number of road junctions per hectare.

mappings do not appear to substantively change the inferences about either the higher 'Black' rates or the differential effect of deprivation on relative risks across the ethnic groups. For some ethnic groupings, there may be a large enough degree of overlap between self and observer identified categories to derive reasonably reliable population rates at a crude level of aggregation. We can therefore be fairly confident that we have identified a higher rate of pedestrian injury in 'Black' children in London compared with others. Alternative mappings also did not substantively change the findings that pedestrian injury rates increase with area deprivation in 'White' and 'Asian' but not 'Black' children, and that these relationships remain after controlling for those features of the road environment that we could measure.

A further cause of numerator-denominator bias might be due to assigning casualties to the LSOAs in which they were injured, rather than to those in which they live (a necessary step due to incomplete postcodes). Although location of collision is a reasonable proxy for location of residence for children in general (Edwards et al., 2007), there may of course be ethnic differences in typical distances travelled by children. If, for instance, 'Black' children who live in deprived areas are more likely to attend schools further away from home than are their 'White' or 'Asian' neighbours, this could partially explain why we observed higher 'Black' child pedestrian injury rates than expected in less deprived areas.

A second potential threat to reliability is data completeness. It is estimated that $30 \%$ of London's road traffic injuries go unreported, and that across the UK $20 \%$ of traffic injuries are unrecorded in STATS19 (Ward et al., 2006). If there are betweengroup differences in the reporting of traffic injuries, this may affect the overall relative differences by ethnicity. However, this under-reporting and under-recording of injuries in STATS19 will only affect our analysis of the relationships between area deprivation, ethnicity and risk if the within-ethnic group propensity to report or record an injury differs by area deprivation. To account for the different patterns of association between deprivation and injury risk in the 'Black' and other ethnic groupings, this would entail injuries to 'Black' child pedestrians (compared to other groups) being relatively over-reported if they occur in the least deprived areas, and relatively under-reported in the most deprived areas. As this may be an unlikely, but not impossible, scenario, we conducted a sensitivity analysis including only those children killed or seriously injured, where reporting biases are less likely to be a threat. The relationship between deprivation and serious injury risk was found to be similar to that using all injuries among 'White' and 'Black' children. There were not enough killed or seriously injured 'Asian' child pedestrians to make similar comparisons.

The most plausible mediators of area effects on injury risk are those relating to the local road environment, and this was confirmed by our study. Our model included those variables known to be related to road injury risk, including the density of A roads (on which the majority of injuries in London occur), density of minor roads, density of road junctions, a measure of residential status and a measure of population density. We found similar results to previous studies: a higher density of A roads, a higher density of road junctions, and more businesses in an area were associated with higher pedestrian injury risk, while a higher density of minor roads was associated with lower injury risk.

There is evidence from broader studies of health and ethnicity that the measure of deprivation chosen makes a significant difference to the level of 'ethnic difference' found (Kaufman et al., 1997; Davey Smith, 2000; Braveman et al., 2001) and that area measures may underestimate the standard of living of minority groups (Davey Smith et al., 2000). The measure of area deprivation used in this study, IMD, may well be prone to these weaknesses, and it is possible that it discriminates less well for 'Black' than other ethnic groups if, for instance, there is less variability between the individual 'Black' households located across different LSOAs than for other groups. Qualitative evidence from studies of housing and social class in London certainly suggests that the relationship between residence and affluence may operate differently across different ethnic groups. Butler and Robson (2003), for instance, in their study of gentrification in Inner London, found few minority ethnic households in the rapidly gentrifying areas they studied, even when located near multicultural areas, and Watt (2005) found individual 'marginal professionals' in social housing who may be more affluent, or have different cultural capital, than the majority of residents locally.

\subsection{What this study adds}

Few studies have examined ethnic differences in pedestrian injury, and the majority of research on ethnicity and transport injury has used mortality data (Schiff and Becker, 1996; Stevens and Dellinger, 2002; Campos-Outcalt et al., 2002, 2003; Braver, 2003; Stirbu et al., 2006). Deaths are rare, and may be atypical of all injury. Compared with other studies of childhood pedestrian injury, our findings are consistent with a Dutch study (Stirbu et al., 2006) that found that minority ethnic children were at higher risk of pedestrian injury mortality, and an Israeli study that identified a higher risk of road traffic injuries for non-Jewish children but interestingly (as in this study) that this higher relative risk disappeared in areas with lower socio-economic status (Savitsky et al., 2007). There is little literature from the UK. One study from Birmingham found that Asian children under 10 years were at higher risk as pedestrians, although this difference was not found for other modes of transport, or at other ages 
(Lawson and Edwards, 1991), suggesting that exposure differences may have explained some of the increased risk. Another UK casecontrol study compared school children injured as pedestrians with those not injured and found that 'non-White' minority ethnic children were over-represented in the 'injured' group, but was not able to identify the contribution of socio-economic factors to this difference (Christie, 1995). By using police data which included an accurate record of the injury location, we were able to both limit the problem of identifying appropriate population denominators, and to avoid bias from potential population differences in health service use. We have been able to estimate reasonably robust population rates for broad ethnic groupings in London and to examine the contribution of area level deprivation, at the level of LSOA, on the relationship between ethnicity and injury risk.

\subsection{Possible mechanisms}

Our study concurs with most international and UK findings that some ethnic minority children are at greater risk of pedestrian injury. However, there is no consensus about precisely who is at risk. The study from Birmingham, for instance, found Asian but not other minority group children to be at increased risk of pedestrian injury (Lawson and Edwards, 1991), whereas our findings suggest that 'Asian' children in London are at relatively low risk and 'Black' children face an increased risk. This suggests that there is nothing fundamental about belonging to a minority ethnic group per se or even to a particular minority ethnic group that increases risk of pedestrian injury. However, our results suggest that the high rate for 'Black' children in London is unlikely to be completely explained by artefacts of inadequate measures of ethnicity or by the association between ethnicity and area deprivation. It is perhaps surprising that whereas lower area deprivation appears to protect 'Asian' and 'White' children from injury risk, it has no similar effect for 'Black' children. There are likely to be complex causal pathways that link belonging to particular ethnic groups living in particular environments and higher child injury rates. Further research is needed on the mechanisms that link ethnicity to road injury risk. Household level deprivation, which might vary in ways that are not reflected in area level deprivation measures, could theoretically influence variables such as mode of transport used, or length of time spent travelling to school or leisure activities. Thus differential exposure is one potential mechanism through which either individual deprivation or cultural factors could influence ethnic differences in risk. There is some suggestion in the road environment analysis for the importance of exposure, given the density of A roads was associated with increased injury risk, as these are likely to have higher traffic flows than either B roads or minor roads, creating more opportunities for car-pedestrian collisions. Existing empirical evidence on the relative amount of pedestrian exposure to roads across different ethnic groups in the UK is mixed (Bly et al., 2006). However, if transport mode, amount of time spent travelling and distance travelled do differ by ethnicity and deprivation, different levels of pedestrian exposure may help to explain our results.

\subsection{Is it useful to look at 'ethnicity' as a variable?}

We have already suggested that our measure of ethnicity is problematic for a study of pedestrian injury risk. Inevitably, in an epidemiological study, the need to aggregate fine-grained choices that could reflect the complexity of ethnicity into broad categories such as 'Black', 'White', or 'Asian' risks masking considerable within-group differences and emphasizing between-group differences. All the broad aggregations we derived collapse a number of population groups that are theoretically very different in terms of likely risks. For instance, rates of car ownership vary across those from Indian, Pakistani and 'Other Asian' backgrounds (Department for Transport, 2006), and the 'White' group includes both UK born individuals and those more recently arrived migrants who may have very different transport mode use. Identifying a high rate of injury among those classified as 'Black' does not identify particular communities which might have disproportionately high rates of injury. Further, without more detailed data on exposure, we have no way of knowing whether this increased risk is the result of greater time exposed as pedestrians, or of behavioural factors. In terms of developing road safety policies that do not exacerbate inequalities in childhood, the aim should be to provide road environments that are safe for the most vulnerable of road users. It is difficult to identify evidence-based interventions which could address such poorly defined groupings as 'Black' children. The implications of the results of this and other studies is that injury risk for particular population groups is unlikely to be generalisable beyond local areas: 'Black' children have been identified as at higher risk in London over the period 1996-2006 but not, for instance, in Birmingham a decade previously (Lawson and Edwards, 1991). Given that area deprivation does increase risk for most population groups, and that the majority of 'Black' child pedestrian injuries do occur in the most deprived areas (simply because this is where most 'Black' children live, as shown in Table 1), road environment improvements that prioritise the most deprived areas are still likely to be the most efficient in terms of strategies to address inequalities. In our dataset, for instance, 36\% of 'White' casualties, $48 \%$ of 'Asian' casualties and $57 \%$ of 'Black' casualties occurred within the three most deprived deciles of LSOAs. However, in terms of understanding the mechanisms that might put some children at greater risk of injury, this analysis by ethnicity is interesting in terms of raising questions for further research that could explore in more detail how exposure to risk might be shaped by ethnicity and place. The key policy challenge remains that of providing safer environments that reduce the risk to vulnerable road users, however often they are exposed to that risk.

\section{Conclusion}

It is clearly not membership of a minority ethnic group per se that puts children at higher risk of being injured, given the different results for different minority groups within this study and compared with others. Furthermore, for those who are at higher risk, it is unlikely to be 'place' of residence that fully explains that additional risk. We cannot, from this secondary analysis, identify what it is about being classified as 'Black' in London that appears to put children at higher risk of road traffic injury than their peers in other ethnic groups, or why living in a less deprived area does not appear to protect them. To do so, we would need more sophisticated understanding of how different components of ethnicity and other structural factors (such as individual deprivation) inter-relate in different places in order to make exposure to injury risk more or less likely for some groups. The measure of ethnicity used in this study was inevitably crude, and not capable of capturing the multiple ways in which ethnic identity is experienced by individuals or communities. Certainly, the aggregations 'Black', 'Asian' and 'White' do not represent any real communities in London, and all three groupings obscure real differences likely to relate to injury risk. However, the overall findings relating to those children identified as 'Black' appeared to be robust. First, 'Black' children appear to be at higher risk than those identified as 'White' or 'Asian'. Second, the well-documented relationship between area deprivation 
and risk did not hold for the 'Black' children: they do not appear to be protected from pedestrian injury risk by living in less deprived areas.

\section{Acknowledgements}

We are grateful to four anonymous referees for very helpful comments on earlier versions of this paper. This work was undertaken by the London School of Hygiene \& Tropical Medicine, who received funding from Transport for London. The views expressed in the publication are those of the authors and not necessarily those of Transport for London. Population estimates were provided by Edmund Klodawski at the Greater London Authority. Traffic flow and speed data were supplied by Martin Obee at Road Network Monitoring, Transport for London. The road network used was OS ITN layer supplied by Transport for London under licence and is copyright Ordnance Survey. 2001 Census data were supplied with the support of ESRC and are Crown copyright.

Competing interests: None declared.

\section{Appendix A. Supporting Information}

Supplementary data associated with this article can be found in the online version at doi:10.1016/j.healthplace.2009.08.002.

\section{References}

ACPO, 2001 Guide to self-defined and descriptive monitoring. Association of Chief Police Officers. 〈http://www.acpo.police.uk/asp/policies/Data/self_define d_ethnicity.doc > (accessed 24 March 2009).

Agran, P.F., Winn, D.G., Anderson, C.T., Del Valle, C.P., 1996. The role of physical and traffic environment in child pedestrian injuries. Pediatrics 98, 1096-1103.

Ahmad, W., Bradby, H., 2007. Locating ethnicity and health: exploring concepts and contexts. Sociology of Health and Illness 29, 795-810.

Bains, B., Klodawski, E., 2007. GLA 2006 Round Ethnic Group Projections. GLA DMAG, London.

Bhopal, R., 1997. Is research into ethnicity and health racist, unsound, or important science?. British Medical Journal 314, 1751-1760.

Bly, P., Jones, K., Christie, N., 2006. Child pedestrian exposure and accidents-furthe analysis of data from a comparative European study. Road Safety Research Report No. 56. Department for Transport, London.

Bradby, H., 2003. Describing ethnicity in health research. Ethnicity and Health 8, $5-13$.

Braver, E.R., 2003. Race, Hispanic origin and socioeconomic status in relation to motor vehicle occupant death rates and risk factors among adults. Accident Analysis and Prevention 35, 295-309.

Braveman, P., Cubbin, C., Marchi, K., Egerter, S., Chavez, G., 2001. Measuring socioeconomic status/position in studies of racial/ethnic disparities: maternal and infant health. Public Health Reports 116, 449-463.

Briggs, N.C., Levine, R.S., Haliburton, W.P., Schlundt, D.G., Goldzweig, I., Warren, R.C., 2005. The Fatality Analysis Reporting System as a tool for investigating racial and ethnic determinants of motor vehicle crash fatalities. Accident Analysis and Prevention 37, 641-649.

Bunn, F., Collier, T., Frost, C., Ker, K., Roberts, I., Wentz, R., 2003. Traffic calming for the prevention of road traffic injuries: systematic review and meta-analysis. Injury Prevention 9, 200-204.

Butler, T., Robson, G., 2003. London Calling: the Middle Classes and the Remaking of Inner London. Berg, Oxford.

Campos-Outcalt, D., Bay, C., Dellapenna, A., Cota, M.K., 2002. Pedestrian fatalities by race/ethnicity in Arizona, 1990-1996. American Journal of Preventative Medicine 23, 129-135.

Campos-Outcalt, D., Bay, C., Dellapena, A., Cota, M.K., 2003. Motor vehicle crash fatalities by race/ethnicity in Arizona, 1990-96. Injury Prevention 9, 251-256.

Cercarelli, L., Knuiman, M., 2002. Trend in road injury hospitalisation rates for Aboriginal and non-Aboriginal people in Western Australia, 1971-97. Injury Prevention 8, 211-215.

Christie, N., 1995. The high risk pedestrian: Socio-economic and environmenta factors in their accidents. Project report 117, Transport Research Laboratory, Crowthorne.

Davey Smith, G., Chaturvedi, N., Harding, S., Nazroo, J., Williams, R., 2000. Ethnic inequalities in health: a review of UK epidemiological evidence. Critical Public Health 10, 375-408.
Davey Smith, G., 2000. Learning to live with complexity: ethnicity, social position and health in Britain and the United States. American Journal of Public Health $90,1694-1698$.

Department for Transport, 2006. Transport Statistics Bulletin. National Travel Survey: 2006. Office for National Statistics, London.

Department of Health, 2003. Tackling Health Inequalities: a Programme for Action. $\mathrm{DOH}$, London.

Duperrex, O., Bunn, F., Roberts, I., 2002. Safety education of pedestrians for injury prevention: a systematic review of randomised controlled trials. British Medical Journal 324, 1129-1134.

Edwards, P., Green, J., Roberts, I., Lutchmun, S., 2006. Deaths from injury in children and employment status in family: analysis of trends in class specific death rates. British Medical Journal 333, 119-121.

Edwards, P., Green, J., Roberts, I., Grundy, C., Lachowycz, K., 2007. Deprivation and Road Safety in London: a Report to the London Road Safety Unit. LSHTM, London (〈http://www.tfl.gov.uk/assets/downloads/deprivation-and-road-saf ety.pdf $>$ (accessed 24 March 2009)).

Edwards, P., Green, J., Lachowycz, K., Grundy, C., Roberts, I., 2008. Serious injuries in children: variations by area deprivation and settlement type. Archives of Disease in Childhood 93, 485-489.

Erens, B., Primatesta, P., 2001. Health Survey for England 1999: The health of Minority Ethnic Groups. The Stationery Office, London.

Factor, R., Mahalel, D., Yair, G., 2008. Inter-group differences in road-traffic crash involvement. Accident Analysis and Prevention 40, 2000-2007.

Grayling, T., Hallam, K., Graham, D., Anderson, R., Glaister, 2002. Streets Ahead: Safe and Liveable Streets for Children. IPPR, London.

Haynes, R., Reading, R., Gale, S., 2003. Household and neighbourhood risks for injury to 5-14 year old children. Social Science \& Medicine 57, 625-636.

HES Online, 2004. How Good is HES Ethnicity Coding and Where do the Problems Lie?. The Information Centre, London (〈http://www.hesonline.nhs.uk $\rangle$ (accessed 24 March 2009))

Karlsen, S., Nazroo, J.Y., 2002. Agency and structure: the impact of ethnic identity and racism on the health of ethnic minority people. Sociology of Health \& Illness 24, 1-20.

Kaufman, J.S., Cooper, R.S., McGee, D.L., 1997. Socioeconomic status and health in blacks and whites: the problem of residual confounding and the resiliency of race. Epidemiology 8, 621-628.

Laflamme, L., Diderichsen, F., 2000. Social differences in traffic injury risks in childhood and youth-a literature review and a research agenda. Injury Prevention 6, 293-298.

Lawson, S., Edwards, P., 1991. The involvement of ethnic minorities in road accidents: data from three studies of young pedestrian casualties. Traffic Engineering \& Control 32, 12-18.

Lyons, R.A., Jones, S.J., Deacon, T., Heaven, M., 2003. Socioeconomic variation in injury in children and older people: a population based study. Injury Prevention 9, 33-37.

Marmot, M.G., Adelstein, A.M., Bulusu, L., 1984. Immigrant Mortality in England and Wales 1970-78: Causes of Immigrant Death by Country of Birth. OPCS, HMSO, London.

Mayor of London, 2001. The Mayor's Transport Strategy. GLA, London.

Mayor of London, 2008. Living well: the Mayor's Draft Health Inequalities Strategy. GLA, London.

Morrison, D.S., Petticrew, M., Thomson, H., 2003. What are the most effective ways of improving population health through transport interventions? Evidence from systematic reviews. Journal of Epidemiology and Community Health 57, 327-333.

Nazroo, J., 1998. Genetic, cultural or socio-economic vulnerability? Explaining ethnic inequalities in health. Sociology of Health and Illness 20, 710-730.

Nazroo, J., 2001. Ethnicity, Class and Health. Policy Studies Institute, London.

Nazroo, J., 2004. 'Ethnicity'. In: Gabe, J. (Ed.), Key Concepts in Medical Sociology. London, Sage.

Noble, M., Wright, G., Dibben, C., Smith, G.A.N., McLennan, D., Antilla, C., Barnes, H., Mokhtar, C., Noble, S., Avenell, D., Gardner, J., Covizzi, I., Lloyd, M., 2004. The English Indices of Deprivation 2004. Report to the Office of the Deputy Prime Minister. Neighbourhood Renewal Unit, London.

Noland, R.B., Quddus, M.A., 2005. Congestion and safety: a spatial analysis of London. Transportation Research Part A 39, 737-754.

Prime Ministers Strategy Unit and The Office of the Deputy Prime Minister, 2005. Improving the prospects of people living in areas of multiple deprivation in England. <http://www.sportni.net/Publications/documents/improving the prospects_of_people_living_in_areas_of_multiple_deprivation_in_England. pdf $>$ (accessed 24 March 2009)

Reading, R., Langford, I.H., Haynes, R., Lovett, A., 1999. Accidents to pre-school children: comparing family and neighbourhood risk factors. Social Science \& Medicine 48, 321-333.

Reimers, A., Laflamme, L., 2005. Neighborhood social and socioeconomic composition and injury risks. A study in the Stockholm County. Acta Paediatrica 94, 1488-1494.

Rivera, F.P., Barber, M., 1985. Demographic analysis of childhood pedestrian injuries. Pediatrics 76, 375-381.

Roberts, I., Norton, R., Jackson, R., Dunn, R., Hassall, I., 1995. Effect of environmental factors on risk of injury of child pedestrians by motor vehicles: a case control study. British Medical Journal 310, 91-94

Savitsky, B., Aharonson-Daniel, L., Giveon, A., 2007. Variability in pediatric injury patterns by age and ethnic groups in Israel. Ethnicity and Health 12, 129-139. 
Schiff, M., Becker, T., 1996. Trends in motor vehicle traffic fatalities among Hispanics, non-Hispanic whites and American Indians in New Mexico, 19581990. Ethnicity and Health 1, 283-291.

Sonkin, B., Edwards, P., Roberts, I., Green, J., 2006. Walking, cycling and transport safety: an analysis of child road deaths. Journal of the Royal Society of Medicine 99, 402-405.

Stevens, J.A., Dellinger, A.M., 2002. Motor vehicle and fall related deaths among older Americans 1990-98: sex, race, and ethnic disparities. Injury Prevention 8, $272-275$.
Stirbu, I., Kunst, A.E., Bos, V., van Beeck, E.F., 2006. Injury mortality among ethnic minority groups in the Netherlands. Journal of Epidemiology and Community Health 60, 249-255.

Ward, H., Lyons, R., Thoreau, R., 2006. Under-reporting of road casualtiesphase 1. Road Safety Research Report No. 69. Department for Transport London.

Watt, P., 2005. Housing histories and fragmented middle class careers: the case of marginal professionals in London. Housing Studies 20, 359-381.

WHO, 2004. World report on road traffic injury prevention. WHO, Geneva. 